\title{
Analysis of Visual Perception of Cinemagraph Images: Focusing on Q Methodology
}

\author{
Kim Young Il $^{1 *}$
}

\begin{abstract}
In the image methodology, cinemagraphs are needed to find out how to think through the empirical studies of the audiences in actual empirical theory. Therefore, this study analyzes what cinemagraph images represent and what groups are inclined to see them. The analytical study aims to reveal the grouping categorized as a preference survey according to the subjectivity study by Q methodology. Research reveals how images should be read and how disparities tend to differ from or agree with those in understanding images. Therefore, four types categorized into $\mathrm{Q}$ analysis through 1: 1 interview using a sample group and using samples showed that human interpretation and cinemagraph images were represented in understanding cinemagraphs.
\end{abstract}

Key Words: Cinemagraph, Q methodology, Visual Perception, Recognition Psychology.

\section{INTRODUCTION}

In the 21st century, multi-platform contents such as motion graphics such as visual image animation are in the spotlight. As image research using visual perception became important, as a result of examining surrounding content, this research began with interest in "Cinemagraph", one of the fusion contents methods. In the past, several pictures are gathered from a picture, consisting of still frames, and the video is a spatial visual and perceptual dimension. This change is due to the combination of content and trends, and technological advances are changing the culture around us.

Cinemagraph, a keyword of this paper, is used as a method of utilizing various content using web mobile technology such as IT, marketing image media IT field, moving some of the images in these static pictures, stimulating audience's curiosity. Therefore, this study measures the visual perception of cinemagraphs and attempts to reveal the subjective feelings of the audience through experiments.

\section{THEORETICAL BACKGROUND}

Manuscript received December 06, 2019; Revised December 26, 2019; Accepted December 30, 2019. (ID No. JMIS-19M-12-050)

Corresponding Author (*): Kim Young Il, 256, Gaon-ro Paju-si, Gyeonggi-do, Republic of Korea, 031-939-9824, kim9668@gmail.com.

${ }^{1}$ Bmarket CEO, Hongik University, Gyeonggi-do, Republic of Korea, kim9668@gmail.com

\subsection{Etymology of Cinemagraph}

Cinemagraphs begin with the approach of the film(cinema), as can be seen from the etymology. It can be seen that the film is a photograph until the movie goes back. The pre-photography era would be painting. As such, the development of images can be understood no matter what fusion content is generated based on historical facts until the era of video today.

The first film began in 1895 with the "cinematographer" filmed invented by the Lumiere brothers on a moving screen. Cinematograph is a combination of the Greek words "Kinema" and "Grafhei." It was originally registered as cynematograghe, but modified ' $\mathrm{Y}$ ' to 'I'. The beginning of the film began that way, and today the film is easily called cinema. Today, cinemagraphs are being used as fusion contents due to the partial combination of pictures and images, and are newly illuminated in the video era and used in advertising digital devices.

\subsection{Q methodology}

The subjectivity study of this paper is designed and tested 
by Q methodology. Q methodology was developed by psychologist William Stephenson (1902 1989) as a way of diagnosing a person's mind [1]. This is a way of expressing what subjective research is considered subjectively or by view of card sourcing, factor analysis and estimating the result of groupings to help the understanding of subjective experience. Inmates usually deal with topics such as love, happiness, politics, psychology, religion, and reason, and use them as a way of extracting objectification from the standpoint of subjective views [2].

Therefore, it is a methodology used when using the same clustering of subjects that are difficult to object with social sciences. After gathering the ideas and opinions of the groups and extracting the factors to determine the highest and lowest levels, the views can be specifically defined as statistical values. In general, the $\mathrm{Q}$ methodology is an alternative research method that responds to factor analysis, and is used in some parts of the social sciences including communication studies and psychotherapy [3]. It is a typology that objectively classifies people's subjectivity through a unique method called Q-sorting. Therefore, this methodology is used to quantitatively analyze the subjective interpretation felt by watching a cinemagraph.

Another such precedent study is "The Effects of Increased Evocativeness from Visual Stimuli in Online Shopping Mall [4]”, “Analysis of Appreciator's Preference Depending on the Difference in Existence \& Unexistence of Movement of Cinemagraph Advertisement" is a study on the preference of visual perception stimulation [5]. "Cinemagraph: the subjective recognition of unfamiliarity" interpreted subjective interpretation in Q methodology and focused on the strangeness of visual perception [6].

\section{SUBJECTIVITY STUDY OF Q METHODOLOGY}

\subsection{Q-Sample Selected}

There are two types of sample selection-unstructured and structural methods-which are randomly divided. In order to select Q-samples, 32 samples were selected after collecting the discretion of cinemagraphs through expert pre-interviews for 10-year experienced workers, one for each master's and Ph.D. Google randomly searched and collected about 112 cinemagraph images evenly from 'Flixel', a representative application for producing cinemagraphs, for about 1 month from October 1 to October 28, 2019. In this study, Q samples corresponding to $2 * 2 * 2 * 2 * 2=32$ final statements, such as intensity, number, area, speed, and perceived position of motion, were selected. Through this, negative, neutral and positive opinions were balanced.

\subsection{P-Sample Selected}

This is best evaluated by five groups. The five groups are as follows. (1) special interest in the subject; (2) dispassionate interest; (3) authoritative or expert in the subject; (4) generally interested in class interest), (5) uninterested [7].

The Q methodology focuses on the value of the meaning of subjectivity and deals with differences in importance within individuals rather than differences between individuals. Therefore, the number of $\mathrm{P}$ samples is not limited, but it provides an opportunity to express subjectivity to $\mathrm{P}$ samplers. Because the purpose of the study is not to produce results for the population, the sampling of the survey subjects is done in a deliberate manner. In this study, P-samples were selected by considering gender, age, education, and occupation based on the criteria presented above. Korean males and females in their 20s and 40s were selected as P-sample subjects with high frequency of using new media and digital images. Then, 39 subjects were interviewed, including 16 males and 23 females, taking into account the Cinemagraph $\mathrm{P}$ sample criteria. These test subjects were randomly selected.

Table 1. P-sample Distribution.

\begin{tabular}{|l|l|l|l|l|l|}
\hline job & $\begin{array}{l}20 \text { 's } \\
(\mathrm{m} / \mathrm{w})\end{array}$ & $\begin{array}{l}30 \text { 's } \\
(\mathrm{m} / \mathrm{w})\end{array}$ & $\begin{array}{l}40 \text { 's } \\
(\mathrm{m} / \mathrm{w})\end{array}$ & $\begin{array}{l}50 \text { 's } \\
(\mathrm{m} / \mathrm{w})\end{array}$ & total \\
\hline student & $6 / 16$ & - & - & - & $6 / 16$ \\
\hline Office & $-/ 2$ & $1 /-$ & $1 / 1$ & & $2 / 3$ \\
\hline $\begin{array}{l}\text { self- } \\
\text { employ } \\
\text { ment }\end{array}$ & - & $1 /-$ & $4 /-$ & $1 /-$ & $6 /-$ \\
\hline $\begin{array}{l}\text { freelan } \\
\text { cer }\end{array}$ & - & $1 / 2$ & $1 / 2$ & - & $2 / 4$ \\
\hline Total & $6 / 18$ & $3 / 2$ & $6 / 3$ & $1 /-$ & $16 / 23$ \\
\hline
\end{tabular}

\subsection{Q-Sorting division}

For about a month, 39 subjects were interviewed at Sangsu-dong, Mapo-gu, Seoul, Ilsan, Goyang-si, Paju-si, and Yangjeong-dong, Jin-gu, Busan. After setting up the survey schedule, they met with the subjects one-to-one and performed Q classification. The process was to code the prepared digital image directly on the desk, show the image directly on the laptop on the html screen, and then hand the image to the subject. The preferences for 32 cinemagraphs in the Q-Class were divided into three groups: the 
affirmative group, the neutral group, and the anti-group. Subjects were asked to write the subjective reasons for each of their preferences and preferences. Normally, the Q sample was classified into three groups, which belonged to either the pros, the neutrals, those who were against. After the Q classification, the Q-segment was recovered and coded into a TXT file. The score was calculated by assigning 1 point to the least preferred and 9 points to the most preferred. In other words, when the most negative, (4) starts with 1 point, 2 points (-3), 3 points (-2), 4 points (1), 5 points (0), 6 points (1), 7 points (2), 8 points (3) and the most positive were 9 points (4). Fig.1 - Fill in the Qsorting fields in step 9. Submitted by checking the never $50 \%$ Always route. Principal component analysis was performed using the QUANL PC program by reflecting the score results in Q sample number order. Used in Microsoft Windows 7, 32bit PC operating system version.

Table 2. Q-sorting.

\begin{tabular}{|l|l|l|l|l|l|l|l|l|l|l|}
\hline Frequency & 2 & 3 & & 4 & 4 & 6 & 4 & 4 & 3 & 2 \\
\hline Score & -4 & -3 & & -2 & -1 & 0 & 1 & 2 & 3 & 4 \\
\hline Count & 1 & 2 & & 3 & 4 & 5 & 6 & 7 & 8 & 9 \\
\hline
\end{tabular}

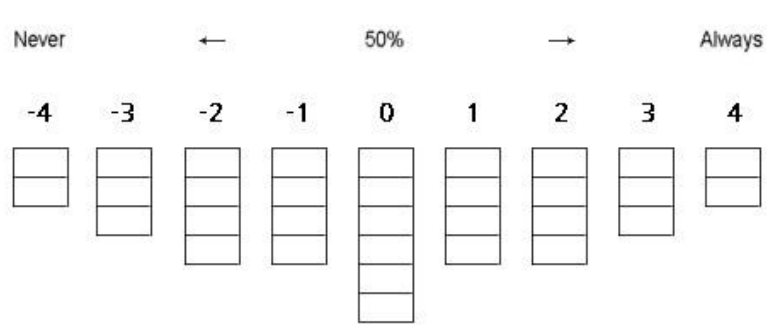

Fig. 1. Q-Sorting Distribution.

\section{EXPERIMENT RESULT}

\subsection{Analysis Result}

On the one hand, the QUANL computer package program used in this study should be theoretically rotated using the Barrimax method. The eigenvalue that determined the number of types was at least 1.00. In addition, correlation coefficients between factors and factor weights were checked to influence the analysis results. After the experiment, the program results were extracted into four types. The eigenvalues of each type were 7.2346, $3.3282,2.3434$, and 1.9315, respectively. The highest number was found in Type 1 because $18 \mathrm{P}$ samples $(\mathrm{N}=18)$ were concentrated in Type 1. And last (fourth type) eigen value exceeding 1.9 seems to be a desirable phenomenon. The explanatory variances by type were $0.1855,0.0853$,
$0.0601,0.495$ and the total was 0.3805 . That is, the four types have about $38 \%$ explanatory power. Since the eigen value or variance of the $\mathrm{Q}$ methodology is affected by the number of subjects, it may be relatively insignificant, unlike the R method.

Table 3. Eigenvalue result.

\begin{tabular}{|l|l|l|l|l|}
\hline & 1 type & 2 type & 3 type & 4type \\
\hline Eigenvalue & 7.2346 & 3.3282 & 2.3434 & 1.9315 \\
\hline Variable & 0.1855 & 0.0853 & 0.0601 & 0.0495 \\
\hline $\begin{array}{l}\text { Cumulative } \\
\text { Variables }\end{array}$ & 0.1855 & 0.2708 & 0.3309 & 0.3805 \\
\hline
\end{tabular}

On the other hand, the correlation coefficient between types shows similarity between types. In this study, the correlation coefficient between type 4 and type 2 was 0.432 , showing the highest correlation. On the other hand, the correlation coefficient between type 3 and type 2 was 0.220 , which was relatively low.

Table 4. Type correlation.

\begin{tabular}{|l|l|l|l|l|}
\hline & 1 type & 2 type & 3 type & 4type \\
\hline 1type & 1.000 & & & \\
\hline 2type & 0.392 & 1.000 & & \\
\hline 3type & 0.310 & 0.220 & 1.000 & \\
\hline 4type & 0.283 & 0.432 & 0.265 & 1.000 \\
\hline
\end{tabular}

The P-sample between types is shown in the table. Type 1 had several students in their 20s, and they were interested in sample 22. Type 2 is interested in sample 16 and is of interest to office workers. Type 3 is interested in No. 26 and there are many women. Type 4 was interested in sample 40 , and there were many men.

\subsection{The Type1 Result}

The first type is the preferred type for clear movements perceived by the eye. The attention to visual perception is clearly reveals that movement attracts the audience first, who initially focuses on one thing, and then the other which meant that visual attention that is less visible. Unclear movements tend to be unfavorable. Therefore, the movements are seen first and do not care about the rest. In short, it is a type that focuses on clear movements. Preferred images and standard scores were 4 (2.27), 1 (1.98), 10 
(1.16), 22 (1.12) and 26 (1.09). On the other hand, unfavorable images and standard scores were $31(-2.07), 3$ (-1.99), and 7 (-1.29), starting from the largest order. In the overall analysis, the image is interpreted as a type concentrating on clear movement through clear and moving boundary lines.

\subsection{The Type2 Result}

Table 5. P-sample between types.

\begin{tabular}{|c|c|c|c|c|c|}
\hline type & $\begin{array}{l}\text { ID- } \\
\text { No }\end{array}$ & age & job & gender & variable \\
\hline $\mathrm{N}=18$ & $\begin{array}{l}22 \\
18 \\
34 \\
19 \\
17 \\
21 \\
3 \\
32 \\
6 \\
5 \\
37 \\
24 \\
20 \\
36 \\
38 \\
11 \\
33 \\
15\end{array}$ & $\begin{array}{l}40 \\
20 \\
20 \\
20 \\
20 \\
20 \\
40 \\
20 \\
40 \\
20 \\
20 \\
20 \\
20 \\
20 \\
20 \\
40 \\
20 \\
20\end{array}$ & $\begin{array}{l}\text { worker } \\
\text { student } \\
\text { student } \\
\text { student } \\
\text { student } \\
\text { student } \\
\text { workers } \\
\text { student } \\
\text { worker } \\
\text { workers } \\
\text { student } \\
\text { student } \\
\text { student } \\
\text { student } \\
\text { student } \\
\text { workers } \\
\text { student } \\
\text { student }\end{array}$ & $\begin{array}{l}\text { Male } \\
\text { Female } \\
\text { Female } \\
\text { Female } \\
\text { Female } \\
\text { Female } \\
\text { Male } \\
\text { Female } \\
\text { Male } \\
\text { Female } \\
\text { Female } \\
\text { Female } \\
\text { Female } \\
\text { Female } \\
\text { Female } \\
\text { Female } \\
\text { Male } \\
\text { Male }\end{array}$ & $\begin{array}{l}1.9877 \\
1.2732 \\
0.8305 \\
0.7836 \\
0.7805 \\
0.7596 \\
0.7454 \\
0.7241 \\
0.6926 \\
0.6247 \\
0.5991 \\
0.5469 \\
0.5139 \\
0.5120 \\
0.4611 \\
0.4574 \\
0.4438 \\
0.4057\end{array}$ \\
\hline $\mathrm{N}=10$ & $\begin{array}{l}16 \\
31 \\
1 \\
4 \\
23 \\
9 \\
35 \\
30 \\
8 \\
14\end{array}$ & $\begin{array}{l}20 \\
20 \\
50 \\
20 \\
40 \\
40 \\
20 \\
20 \\
30 \\
30\end{array}$ & $\begin{array}{l}\text { student } \\
\text { student } \\
\text { workers } \\
\text { workers } \\
\text { workers } \\
\text { workers } \\
\text { student } \\
\text { student } \\
\text { workers } \\
\text { workers }\end{array}$ & $\begin{array}{l}\text { Male } \\
\text { Female } \\
\text { Male } \\
\text { Female } \\
\text { Male } \\
\text { Female } \\
\text { Female } \\
\text { Female } \\
\text { Male } \\
\text { Male }\end{array}$ & $\begin{array}{l}1.4493 \\
0.9669 \\
0.7959 \\
0.7548 \\
0.7460 \\
0.7188 \\
0.6713 \\
0.5617 \\
0.5002 \\
0.3399\end{array}$ \\
\hline $\mathrm{N}=5$ & $\begin{array}{l}26 \\
12 \\
39 \\
25 \\
27\end{array}$ & $\begin{array}{l}20 \\
40 \\
30 \\
20 \\
20\end{array}$ & $\begin{array}{l}\text { student } \\
\text { workers } \\
\text { workers } \\
\text { student } \\
\text { student }\end{array}$ & $\begin{array}{l}\text { Female } \\
\text { Female } \\
\text { Female } \\
\text { Female } \\
\text { Male }\end{array}$ & $\begin{array}{l}1.2778 \\
0.9917 \\
0.8032 \\
0.7121 \\
0.4132\end{array}$ \\
\hline $\mathrm{N}=6$ & $\begin{array}{l}10 \\
28 \\
29 \\
7 \\
13 \\
2\end{array}$ & $\begin{array}{l}40 \\
20 \\
20 \\
30 \\
30 \\
40\end{array}$ & $\begin{array}{l}\text { workers } \\
\text { Student } \\
\text { Student } \\
\text { workers } \\
\text { workers } \\
\text { workers }\end{array}$ & $\begin{array}{l}\text { Male } \\
\text { Male } \\
\text { Male } \\
\text { Male } \\
\text { Female } \\
\text { Male }\end{array}$ & $\begin{array}{l}1.1640 \\
1.0172 \\
0.5591 \\
0.4155 \\
0.7467 \\
0.1907\end{array}$ \\
\hline
\end{tabular}

Table 6. Type1-Array of Z-score ( \pm 1.00 More Than).

\begin{tabular}{|c|c|c|}
\hline No & Cinemagraph & Z-score \\
\hline 4 & & 2.27 \\
\hline 1 & & 1.98 \\
\hline 10 & & 1.16 \\
\hline 22 & & 1.12 \\
\hline 26 & & 1.09 \\
\hline 31 & & -2.07 \\
\hline 3 & & -1.99 \\
\hline 7 & & -1.29 \\
\hline
\end{tabular}

The second type is the small motion type, which is about $10 \%$ of the movement. I prefer to be perceived as a small movement represented by the cinema graph. This is a surprise after discovering that there was no movement; yet, it was discovered.

The stimulus of movement was changed into a sophisticated expression of the cinemagraph, showing a positive attitude. Preferred images and standard scores were 1 (1.98), 9 (1.33), 5 (1.28) and 26 (1.08). The unfavorable images and standard scores were 3 (-1.98), 31 (-1.81), 30 ($1.48)$, and $12(-1.25)$. Sensory movement is the type of movement in harmony with attitudes stimulated by emotional satisfaction in the overall interpretation.

\subsection{The Type 3 Result}

In the third type, the motion and image correspond. The image was recognized as a video from the beginning which suggests that this type prefers natural rendering. 
Table 7. Type2-Array of Z-score ( \pm 1.00 More Than).

\begin{tabular}{|c|c|c|}
\hline No & Cinemagraph & Z-score \\
\hline 1 & & 1.98 \\
\hline 9 & Otcos (2) & 1.33 \\
\hline 5 & & 1.28 \\
\hline 26 & & 1.08 \\
\hline 3 & & -1.98 \\
\hline 31 & & -1.81 \\
\hline 30 & & -1.48 \\
\hline 12 & & -1.25 \\
\hline
\end{tabular}

He did not like the unfamiliar image of the strangeness chosen in the non-preferred way and showed a natural attitude with a positive attitude. Preferred images and standard scores were ranked 22nd (1.41), 5th (1.39) and 27 th (1.07). By contrast, the non-preferred images and standard scores were $16(-1.91), 8$ (-1.63), 2 (-1.45), 19 ($1.32), 4(-1.24)$, and 25 (-1.02). In interpreting the image, it is interpreted as a type that prefers common sense, scientific rationality, and familiarity, and prefers an unstable state.

\subsection{The Type4 Result}

They prefer strong, fast images, prefer artificial, colorful movements, and prefer dynamic movements. The image is visually strong, prefers movement with wide speed and an active area, and prefers artificial movement. The preference images and standard scores were 29 (2.50), 21 (1.83), 24 (1.46), and 15 (1.13). On the contrary, the unfavorable images and standard scores were $3(-2.00), 31$ $(-1.69), 27(-1.38)$, and 30 (-1.19). When viewing an image, it is interpreted as a type that prefers colorful and strong contrast effect and fast and strong movement.
Table 8. Type3-Array of Z-score ( \pm 1.00 More Than).

\begin{tabular}{|c|c|c|}
\hline No & Cinemagraph & Z-score \\
\hline 22 & & 1.41 \\
\hline 5 & & 1.39 \\
\hline 27 & & 1.07 \\
\hline 16 & & -1.91 \\
\hline 8 & & -1.63 \\
\hline 2 & & -1.45 \\
\hline 19 & has & -1.32 \\
\hline 4 & & -1.24 \\
\hline 25 & & -1.02 \\
\hline
\end{tabular}

\subsection{Argument}

The types that were excluded from the experiment and not extracted must also be outlined. In contrast to the third type, it is a type that shows an attitude of preferring an unfamiliar movement. Regarding 19 or 8, ID No. 1 said, "The narrative element of movement was good. The man to be moved was stopped and screaming only as a girl stimulates the imagination and makes me feel good." Regarding number 5, subject ID 17 explains the unextracted type, "I expressed a fresh point of view that I had never imagined this place moving".

\section{CONCLUSION}

This study consisted of 32 Q-samples and subjective Q classification to $39 \mathrm{P}$-samples. Four types were identified through the QUANL program. In the first type, the audience sees the movement first, and the movement of the cinemagraph is the type in which the visual perception is prominent. The movement first attracts the audience, and 
the preferences for focusing on the movement and moving and not moving the cinemagraph are obvious.

The second type is a type that prefers a refined sense of movement and can be said to be a type that is interpreted in abundance with the emotion of the receiver. It is a surprise to discover after a small movement, but not later. The audience interprets the sensory movement as a tendency. The second type of prisoner showed a positive attitude to the sensory movements produced in the subjective interview of $\mathrm{Q}$ factor.

Table 9. Type4-Array of Z-score ( \pm 1.00 More Than).

\begin{tabular}{|c|c|c|}
\hline No & Cinemagraph & Z-score \\
\hline 29 & & 2.50 \\
\hline 21 & & 1.83 \\
\hline 24 & & 1.46 \\
\hline 15 & & 1.13 \\
\hline 3 & & -2.00 \\
\hline 31 & & -1.69 \\
\hline 27 & & -1.38 \\
\hline 30 & & -1.19 \\
\hline
\end{tabular}

The third type is Similar to the video. It is not a picture, I prefer to watch the video. Natural movements can be seen as a positive attitude. It is said that he likes natural movements such as being uncomfortable with unfamiliar appearances, embarrassed by unnaturalness, and scared.

The fourth type is the preferred type for movements that provide new sights, splendor and dynamic motion. Cinemagraphs, which have been met with pictures and videos, offer a new genre of sights and are interpreted as a favorite type of sights of various movements by the influence of other new fusion genres of pictures and videos.

Cinemagraphs were expressed according to the movement characteristic criteria, which changed according to the interpretation of the audience. Although the type changes with the change of movement, this study focuses on movement, but there are many variables in the image. Comparing movement with non-movement naturally resulted in a focus on movement.

\section{REFERENCES}

[1] Ellingsen, I.T., Storksen, I., \& Stephens, P. "Q methodology in social work research." International Journal of Social Research Methodology, vol. 13, no. 5, pp. 395-409, 2010.

[2] Suneun kim, "Theoretical Background and Critical Review of Q Methodology" International Journal of Social Research Korean Society for Policy Analysis and Evaluation, vol. 9, no. 2, pp. 201-216, 1999.

[3] Stephenson, W, "The study of behavior; Q-technique and its methodology", University of Chicago Press, 1953.

[4] Ji-seob Park, "Effects of Increased Evocativeness from Visual Stimuli in Online Shopping Mall", M.S.Department Business Administration, Ajou University, 2014.

[5] Jong-Moo kim, “Analysis of Appreciator's Preference Depending on the Difference in Existence \& Unexistence of Movement of Cinemagraph Advertisement", International Journal of the Korean Society of Design Culture, vol.??, no. ??, pp. ??-??, 2017.

[6] Young-Il kim, "Cinemagraph", Ph.D .Department of Film \& Digital Media Design, Hongik University, 2019.

[7] Heunggyu kim, "Q methodology", in communication books, 2008.

\section{Author}

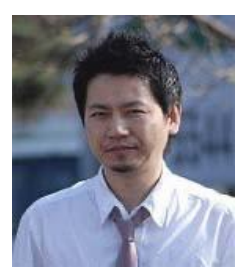

Yong-Il.Kim(kim9668@gmail.com) has born in Busan, Republick of Korea, in May. 1976. He received his M.Sc. from the Art of Keimyung University Visual Communction Design Graduation Korea (1996). In 2007 he graduated from school Hongik University Interaction Design Graduation School (M.S) \& he graduated his Ph.D. in Hongik University, Dept. of Film and Digital Media Design Graduation School. He is currently Bmarket CEO (2015 2019). He went to company to UI/UX designer team leader e-commerce for wemekeprice.com (2015), in Samsung affiliated company OpenTide china UI/UX designer team leader (2014), SKcommunication NATE/Cyworld/11st.co.kr e-commerce UI/UX design team leader (2010) and CJ Homeshopping ecommerce UI/UX designer (2005). He is UI/UX designer in Korea and cooperates with many papers. He is also active in the media art exhibition and art field. It is a media transition group called VIOND. It is a team that presents visual media and interaction design art. Since 2018, he has continued to work on a number of works. He is also writing a book that shares ui design graphic design IT information knowledge and is active in a wide range of knowledge and works. Era of Quaternary Industry Video What is 
Journal of Multimedia Information System VOL. 6, NO. 4, December 2019 (pp. 251-258): ISSN 2383-7632 (Online) http://doi.org/10.33851/JMIS.2019.6.4.251

the interest of users or consumers, and how they are interested in analyzing the users who use them. It is working in conjunction with the digital design platform to discover and study regularity or new laws in any field from the UX perspective. The reason for the interest in the field is that UX exists in VR / AR and UX exists in e-commerce. This is because the market and visual related design fields are expected to have a big impact on the Fourth Industrial Revolution. In the future, we will continue to study the convergence design of new fields and existing ones. 
